\title{
Polydipyrrole- and polydicarbazole-nanorods as new nanosized supports for DNA hybridization $\dagger$
}

\author{
Received (in Cambridge, UK) 17th February 2005, Accepted 20th June 2005 \\ First published as an Advance Article on the web 14th July 2005 \\ DOI: 10.1039/b502483h
}

Jean-Paul Lellouche, ${ }^{* a}$ Senthil Govindaraji, ${ }^{a}$ Augustine Joseph, ${ }^{a}$ Jyongsik Jang ${ }^{* b}$ and Kyung Jin Lee ${ }^{b}$

Novel functional polydipyrrole- and polydicarbazole nanorods have been AAO template-synthesized from $\mathrm{COOH}$ dipyrrole/-dicarbazole monomers using Vapor Deposition and Liquid Phase Polymerizations (VDP and LPP). They were tested as insoluble supports for covalent DNA attachment and hybridization.

Amongst various classes of nanomaterials, conducting polymers (CPs)-based nanomaterials such as polymeric nanotubes/rods have recently piqued scientific interest due to their potential use in various biomedical applications. ${ }^{1-3}$ In general, CPs have been (electro)chemically template-synthesized from simple nonfunctional oxidizable monomers, such as pyrrole, aniline, and thiophene within nanoporous membranes, resulting in solid CPs-based nanorods and hollow nanotubules. ${ }^{1-3}$ If desired, membrane dissolution can release monodispersed CPs-based nanorods and/or nanotubules for further processing. Both anodized aluminum oxide (AAO) and track-etched polyester membranes have been used, since they contain a high density of size-defined, well-separated, discrete nanopores as shape-defining nanoreaction vessels. ${ }^{4-6}$ Astonishingly, the oxidative templatesynthesis polymerization of more sophisticated, oxidizable monomers having chemical functionalities has never been reported. Depending on monomer structure, the resulting CPs-based nanotubes/rods should possess functional groups protruding from surfaces. These groups may be made accessible within polymeric matrices themselves for post-polymerization derivatizations.

In this work, we report the preparation of novel polymeric CPs-based polycarboxylated functional nanorods that were template-synthesized from dipyrrole (DPy) and dicarbazole (DCb) monomers $\mathbf{3}^{7}$ and $\mathbf{4}^{\mathbf{8}} \mathbf{6}^{89}$ (Scheme 1). These new DPyand DCb-precursors are bis-heterocyclic and mono-/bis-carboxylated. DCb-monomers of type $4,{ }^{8}$ that contained $\mathrm{NH}_{2}$-sensitive pentafluorophenyl esters exchangeable by surface $\mathrm{NH}_{2}$ groups of enzymes, have been electropolymerized onto $\mathrm{Pt} / \mathrm{Au}$ microelectrodes. ${ }^{8}$ In addition, magnetically responsive nanocomposites of a magnetite-pDPy/pDCb core-shell morphology were readily prepared by chemical oxidation of a range of DPy-/DCb-monomers

${ }^{a}$ Bar-Ilan University, Department of Chemistry, Ramat-Gan, 52900, Israel.E-mail: lellouj@mail.biu.ac.il; Fax: 972-3-535 1250;

Tel: $972-3-5318324$

${ }^{b}$ Hyperstructured Organic Materials Research Center and School of Chemical Engineering, Seoul National University Shinlimdong 56-1, Seoul,151-742,Korea.E-mail: jsjang@plaza.snu.ac.kr.

Fax: (+82)2-888-1604; Tel: (+82)2-880-7069

† Electronic supplementary information (ESI) available: experimental description of fabrication of pDPy-/pDCb-nanorods. See http://dx.doi.org/ $10.1039 / \mathrm{b} 502483 \mathrm{~h}$

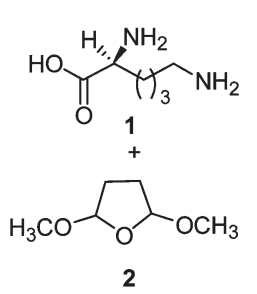

$\mathrm{AcOH}, \mathrm{NaOAc}$
$\mathrm{H}_{2} \mathrm{O}, \mathrm{DCE}, 76^{\circ} \mathrm{C}$, $3 \mathrm{~h}, 70 \%$

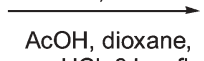
conc. $\mathrm{HCl}, 3$ h-reflux rt-overnight, $25 \%$
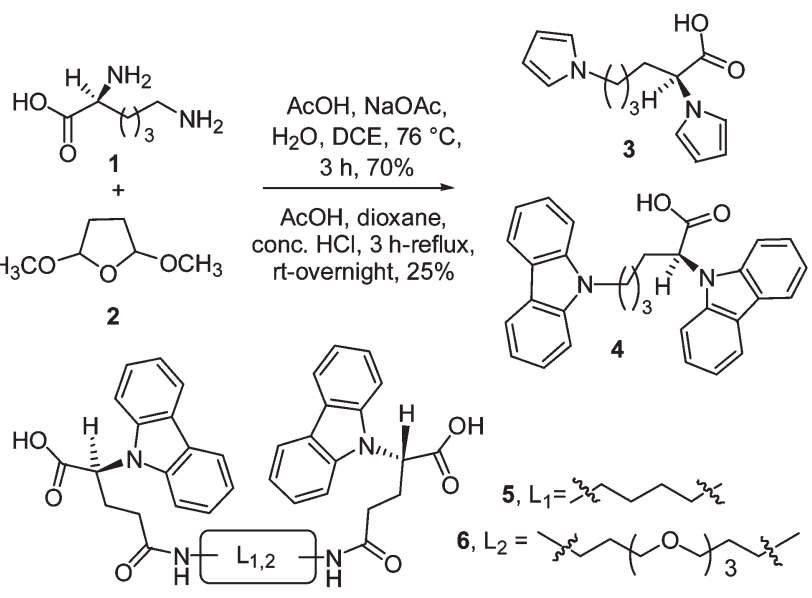

Scheme 1 Structures of DPy- and DCb-monomers 3 and 4-6.

of type 3-6 around nanosized magnetite particles. ${ }^{10}$ In all these examples, (electro)chemically stable polymer deposits resulted from a polymer reticulation caused by the innovative bisheterocyclic chemical design of monomers. It should be noted that simple $N$-substituted mono carbazoles could not afford electrochemically stable polycarbazole films but rather shorter soluble tetrameric polycarbazole chains. ${ }^{11,12}$ Additionally, since carbazoles are more difficult to (electro)chemically oxidize than pyrroles, we identified ceric ammonium nitrate (CAN) as a unique oxidant able to efficiently polymerize bis-heterocyclic DCbmonomers around magnetite nanoparticles. ${ }^{10}$

The two COOH-containing DPy- and DCb-monomers 3 and $\mathbf{4}$ have been synthesized by condensing L-lysine $\mathbf{1}$ with 1,4-dimethoxy tetrahydrofuran 2 using a modified Clauson-Kaas reaction ${ }^{7,8}$ (Scheme 1). The two C2-symmetrical bis-COOH DCb-monomers 5 and $\mathbf{6}$ were readily obtained in a short three-step synthesis. ${ }^{9,10} \mathrm{~A}$ similar modified Clauson-Kaas reaction has been performed on the protected L- $\alpha$-benzyl glutamate, followed by DCCHOBt mediated diamidation of the resulting benzylated pyrrole-/carbazole-glutamates using linkers $\mathbf{L}_{\mathbf{1 , 2}}$. Subsequent debenzylation $(10 \% \mathrm{Pd} / \mathrm{C}, 1 / 4 \mathrm{v} / \mathrm{v}$ cyclohexene $/ i$-PrOH$)$ of protected DPy-/DCb-intermediates cleanly afforded DPy- and DCbmonomers 5 and 6 (32-33\% overall yields).

Monomers DPy-3 and DCb-4 have been chemically polymerized within nanosized pores of AAO membranes (Whatman International Ltd., Anodisc 25; $\varnothing=21 \mathrm{~mm}, 3$ membranes/ experiment, $60 \mu \mathrm{m}$ thickness, $100 \mathrm{~nm}$ average pore size, $10^{9}$ pores $\mathrm{cm}^{-2}$ pore density) by vapor deposition (VDP, ${ }^{13,14}$ $\mathrm{FeCl}_{3}$ oxidant) and liquid phase (LPP, ${ }^{1,15}$ CAN oxidant) polymerization techniques. Detailed experimental procedures for 
the preparation of $\mathrm{pDPy} / \mathrm{pDCb}$-nanorods are described in the ESI. $\uparrow$ The resulting polycarboxylated $\mathrm{pDPy}-/ \mathrm{pDCb}$-nanorods are new nanosized insoluble polymeric supports compatible for DNA hybridizations. To the best of our knowledge, the preparation of such functional CPs-based nanorods from chemically more sophisticated COOH-containing DPy-/DCb-monomers, and their further use in DNA hybridizations, have never been reported.

The FT-IR spectrum (Bomem MB 100 FT-IR spectrometer, $\mathrm{KBr}$ pellet) of pDPy-nanorods, fabricated by the VDP method, showed the characteristic large peak of a polycationic doped $\pi$-conjugated polypyrrole system, e.g. the conjugated $\mathrm{C}-\mathrm{N}$ stretching at $1384 \mathrm{~cm}^{-1}$. ${ }^{16}$ The $\mathrm{C}-\mathrm{H}$ and $\mathrm{O}-\mathrm{H}$ (COOH function) stretchings, respectively at $[2853,2930,2960]$ and $3443 \mathrm{~cm}^{-1}$, further supported the formation of polycarboxylated pDPy-nanorods.

Fig. 1A represents both SEM and TEM images of smooth and uniform meniscus-ended pDPy-nanorods (SEM and TEM: JEOL JSM-6700F Scanning Electron and JEOL EM-2000 EX II cast onto silicon wafers and carbon-coated copper grids, respectively). Combined SEM and TEM analyses unambiguously proved that they are rather solid nanorods. Interestingly, simple unsubstituted pyrrole produced only hollow nanotubes, under similar polymerization conditions. Most likely, this difference arises from the bis-heterocyclic nature of DPy-monomer 3 that allowed a twodimensional reticulating polymer chain growth both along and bent from the pore axis. The average diameter $(155.0 \mathrm{~nm})$, length $(1.70 \mu \mathrm{m})$, and aspect ratio (ca. 11) of $\mathrm{pDPy}(3)$-nanorods were calculated from 50 counted nanorods. The average length was far from a full spanning through AAO membrane nanopores.

Since less volatile DCb-monomer 4 was freely soluble in $\mathrm{CH}_{2} \mathrm{Cl}_{2}$, the more appropriate LPP technique has been used to effect its oxidative polymerization in CAN-loaded AAO template membranes. $\dagger$

The FT-IR spectrum of purified pDCb(4)-nanorods had characteristic vibration peaks of indoles in the range of 1630 $1540 \mathrm{~cm}^{-1}$, and conjugated C-N-C stretchings at $1442 \mathrm{~cm}^{-1} \cdot \mathrm{C}-\mathrm{H}$ and $\mathrm{O}-\mathrm{H}$ stretchings appeared at 2853, 2930 and $2960 \mathrm{~cm}^{-1}$ and
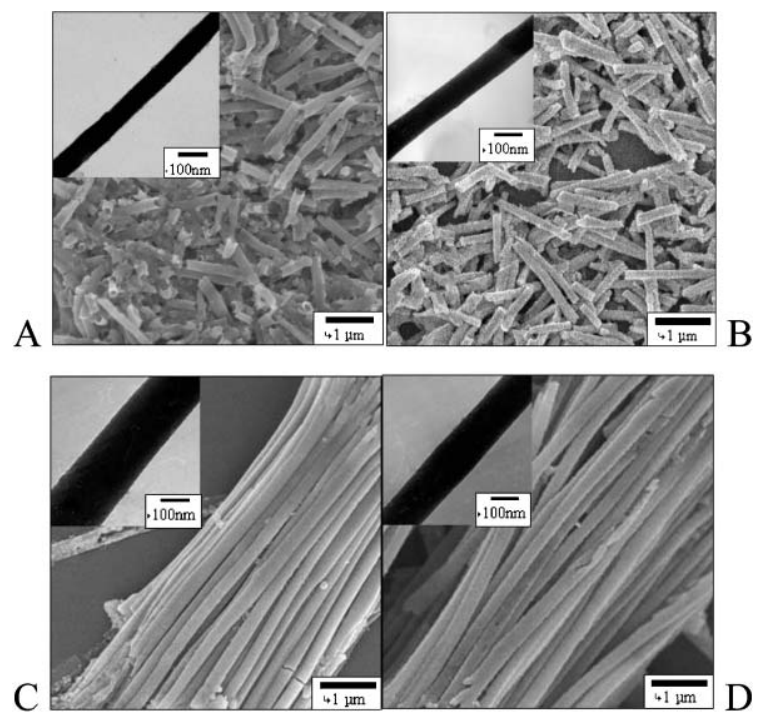

Fig. 1 A-D. SEM and TEM (inset) images of $\mathrm{pDPy}(\mathbf{3})$-nanorods (A) and of $\mathrm{pDCb}(\mathbf{4}-\mathbf{6})$-nanorods (B-D).
$3443 \mathrm{~cm}^{-1}$ respectively. SEM and TEM pictures (Fig. 1B) showed solid uniform pDCb-nanorods possessing rather smooth surfaces. They were characterized by an average diameter of $132.8 \mathrm{~nm}$ and length of $3.60 \mu \mathrm{m}$ (50 counted nanorods, average aspect ratio of $c a$. 27), again the length being far from the specified membrane thickness. Interestingly, $\mathrm{pDPy}(\mathbf{3})-/ \mathrm{pDCb}(4)$-nanorods did not aggregate, most likely due to repulsive charge stabilization (polycationic polymer skeleton and protruding anionic carboxylates).

Similar attempts to prepare $\mathrm{pDCb}(\mathbf{5 / 6})$-nanorods from $\mathrm{DCb}$ monomers 5 and $\mathbf{6}$ by LPP were not satisfactory due to monomer insolubility in common organic solvents including $\mathrm{CH}_{2} \mathrm{Cl}_{2}$. Nevertheless, slightly more vigorous VDP conditions than those used for $\mathrm{pDPy}(3)$-nanorods, $\uparrow$ were found successful, using $\mathrm{CAN}$-charged AAO template membranes. $\uparrow$ Resulting $\mathrm{pDCb}(\mathbf{5} / \mathbf{6})$ nanorods were similarly characterized by FT-IR, SEM and TEM microscopy analyses. FT-IR spectroscopy revealed characteristic vibration peaks at $1640-1540$, and $1473 \mathrm{~cm}^{-1}$ (indole ring), at $1384 \mathrm{~cm}^{-1}$ (conjugated C-N stretchings), at $1680 \mathrm{~cm}^{-1}(\mathrm{~N}-\mathrm{H}$ stretchings), and at $3443 \mathrm{~cm}^{-1}$ (O-H stretchings). In the case of $\mathrm{pDCb}(6)$-nanorods, additional characteristic peaks appeared for symmetric $\mathrm{C}-\mathrm{O}\left(-\mathrm{OCH}_{2}-\right)$ and $\mathrm{C}-\mathrm{H}$ (ether group) stretchings at $1130 \mathrm{~cm}^{-1}$ and $2835-2955 \mathrm{~cm}^{-1}$ respectively. SEM and TEM images showed smooth surfaces of $\mathrm{pDCb}(5)-$ and pDCb(6)-nanorods (Figs. 1C and 1D respectively). Their calculated average lengths $(5.0$ and $7.0 \mu \mathrm{m})$ and diameters (190.0 and $130.0 \mathrm{~nm}, 50$ counted $\mathrm{pDCb}(\mathbf{5 / 6})$-nanorods) resulted in high average aspect ratios $c a .26$ and 53 , respectively.

The four polycarboxylated $\mathrm{pDPy}(\mathbf{3})$ - and $\mathrm{pDCb}(\mathbf{4}-\mathbf{6})$-nanorods have been separately tested for DNA covalent immobilization and hybridization using an HRP-based enzymatic amplifying system (HRP: Horse Radish Peroxidase, Scheme 2 and ESI $\dagger$ ). First an amine-modified 20-mer oligonucleotide $\mathrm{NH}_{2}$-DNA $\mathrm{H}_{2} \mathrm{~N}$ $\left(\mathrm{CH}_{2}\right)_{12}{ }^{5^{\prime}}$ GCACTGGGAGCATTGAGGCT (14.1 nmol), that characterizes the 20210 mutation in the Human Factor II gene, ${ }^{17}$ has been covalently attached onto $\operatorname{pDPy}(3)-$ and $\operatorname{pDCb}(4$ 6)-nanorods $(600.0 \mu \mathrm{g})$ following $\mathrm{COOH}$ activation by the water-soluble carbodiimide EDC (EDC: $N^{\prime}$-(3-dimethylaminopropyl)- $N$-ethyl-carbodiimide, $0.4 \mathrm{M}$ MES buffer at $\mathrm{pH} 5.0,2 \mathrm{~h}$ incubation at $\left.20^{\circ} \mathrm{C}\right) .{ }^{18,19}$

After hybridization with the fluoresceine-labeled antisense 20mer oligonucleotide FITC-DNA (fluoresceine- ${ }^{5}$ AGCCTCAATGCTCCCAGTGC, $10 \mathrm{~min}, 60^{\circ} \mathrm{C}$, six parallel experiments, $50.0 \mu \mathrm{g}$ of nanorods per Elisa plate well/experiment), an anti-FITC HRPlabeled mouse monoclonal antibody was added and incubated (10 min, $20{ }^{\circ} \mathrm{C}$ ). After addition of the HRP substrate TMB (3,3',5,5'-tetramethyl-benzidine, Aldrich), both pDPy- and

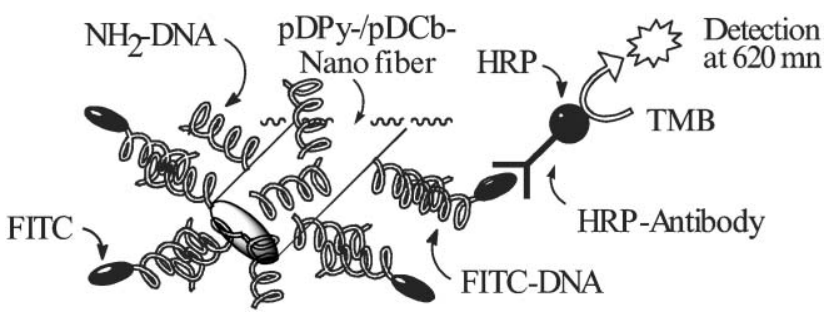

Scheme 2 DNA covalent attachment onto pDPy-/pDCb-nanorods and hybridization. 
DNA Hybridization onto pDPy-/pDCb-Nanorods

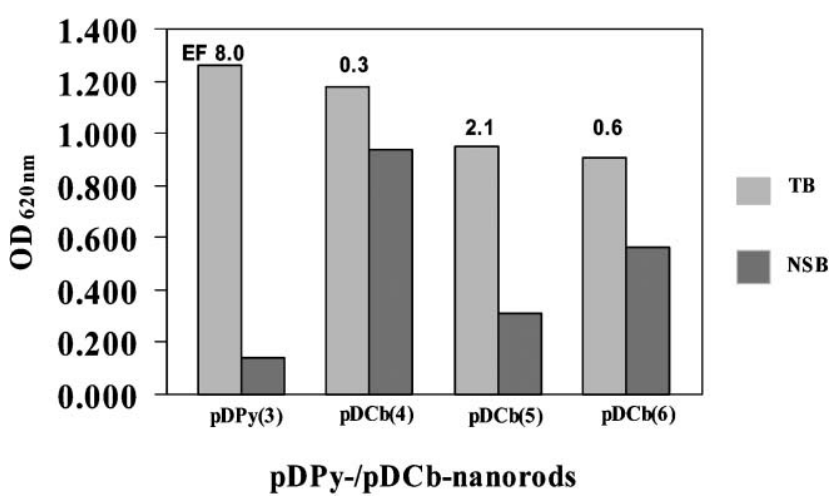

Fig. 2 Efficiency data for DNA hybridizations performed onto pDPy-/pDCb-nanorods.

pDCb-immobilized amplifying enzymatic constructs were reacted $\left(5 \mathrm{~min}, 20^{\circ} \mathrm{C}\right.$ ) before visible reading at $620 \mathrm{~nm}$ (Elisa Plate Reader Anthos ht II, total binding TB, sextuple experiments). Similarly, six parallel experiments that omitted the FITC-DNA complementary sequence allowed us to evaluate the nonspecific binding (NSB) data that characterized the affinity of each tested pDPy(3)- and $\mathrm{pDCb}(4-6)$-nanorods (50.0 $\mu \mathrm{g}$ per Elisa plate well/experiment) to physically adsorb the reporter anti-FITC HRP-labeled antibody. Resulting averaged data (Fig. 2) clearly demonstrated that $\mathrm{pDPy}(3)-/ \mathrm{pDCb}(\mathbf{4}-\mathbf{6})$-nanorods enabled covalent DNA immobilization and hybridization although with variable efficiencies that depended on pDPy-/pDCb-series of nanorods. Accordingly, pDPy(3)-nanorods exhibited a very low affinity for the reporter HRP-labeled antibody in the $8-10 \%$ range (low NSB). It resulted in a high efficiency factor $\mathrm{EF}(\mathrm{EF}=(\mathrm{TB}-\mathrm{NSB}) / \mathrm{NSB}=8.0)$ for these nanorods. On the contrary, more hydrophobic $\mathrm{pDCb}(4$ 6)-nanorods disclosed poor to moderate $\mathrm{EFs}$ in a 0.6-2.1 range due to much higher NSB signals. Further use of pDCb-nanorods for the detection of DNA hybridization will require additional passivation steps.

In conclusion, we have fabricated, for the first time, functional polyCOOH-pDPy(3)-/pDCb(4-6)-nanorods by template-synthesis using AAO membrane templates. Nanorod-supported DNA hybridizations have been validated by an enzymatic HRP-based amplifying system opening an interesting avenue toward DNAbased self-assembly processes of polymeric nanorods for supramolecular biosensing assemblies.
This work has been partly funded under both Vth [CHEMAG $\left(\mathrm{n}^{\circ}\right.$ GRD2-2000-30122)] and VIth [NACBO (n ${ }^{\circ}$ NMP3-2004500802-2)] Framework European projects. It has also been supported by the Brain-Korea 21 Program (Korea Ministry of Education), and the Hyperstructured Organic Materials Research Center of the Seoul National University.

\section{Notes and references}

1 C. R. Martin, Science, 1994, 266, 1961-1966.

2 S. B. Lee, D. T. Mitchell, L. Trofin, T. K. Nevanen, H. Söderlund and C. R. Martin, Science, 2002, 296, 2198-2200.

3 A. Huczko, Appl. Phys. A, 2000, 70, 365-376.

4 M. Steinhart, J. H. Wendorff, A. Greiner, R. B. Wehrspohn, K. Nielsch, J. Schilling, J. Choi and U. Gösele, Science, 2002, 296, 1997.

5 M. Steinhart, R. B. Wehrspohn, U. Gösele and J. H. Wendorff, Angew. Chem. Int. Ed., 2004, 43, 1334-1344.

6 C. R. Martin, Chem. Mater., 1996, 8, 1739-1746.

7 DPy-monomer 3: K. Périé, V. Strokhin, R. S. Marks and J.-P. Lellouche, in $43^{\text {rd }}$ OHOLO Conference Proceedings, Eilat, October 10-14, 1999, ed. Z. Liron, A. Bomberg and M. Fisher, Kluwer Academic/Plenum Publishers, New York, 2001, pp. 225-233.

8 DCb-monomer 4: K. Périé, R. Marks, S. Szunerits, S. Cosnier and J.-P. Lellouche, Tetrahedron Lett., 2000, 41, 3725-3729.

9 Full details on the preparation and the analytical/spectroscopic characterization of DCb-monomers $\mathbf{5}$ and $\mathbf{6}$ will soon be published in a forthcoming article.

10 J.-P. Lellouche, N. Perlman, A. Joseph, G. Senthil, L. Buzhansky, A. Yakir and I. Bruce, Chem. Commun., 2004, 560-561.

11 A. Desbene-Monvernay, P. C. Lacaze and M. Delamar, J. Electroanal. Chem., 1992, 334, 241-246.

12 K. Lmimouni, C. Legrand and A. Chapoton, Synth. Met., 1998, 97, $151-155$.

13 J. Jang and J. H. Oh, Chem. Commun., 2004, 882-883.

14 This VDP experimental set-up has been previously described: J. Jang and B. Lim, Angew. Chem. Int. Ed., 2003, 42, 5600-5603.

15 C. R. Martin, Acc. Chem. Res., 1995, 28, 61-68.

16 A. Deronzier and J. C. Moutet, Curr. Top. Electrochem., 1994, 3, 159-200.

17 S. R. Poort, F. R. Rosendaal, P. H. Reitsma and R. M. Bertina, Blood, 1996, 88, 3698-3703.

18 A typical protocol for DNA attachment/hybridization onto polymeric nanorods has been reported in the ESI. It includes details about specific solutions and buffers used in these experiments.

19 The covalent attachment of the $\mathrm{NH}_{2}$-DNA capture probe onto $\mathrm{pDPy} / \mathrm{pDCb}$-nanorods is quantitative in these conditions according to the following data. First, concentrations of $\mathrm{COOH}$ groups accessible for covalent binding have been measured after the covalent intake of an aminated fluorescent dansylated DNSA probe (detailed structure given in the ESI) reacted in DNA-like conditions (HPLC assay). Depending on nanorods, these values have been found in a range of $750-805 \mathrm{nmol} \mathrm{mg}{ }^{-1}$ of nanorods, which much exceeded the quantity of reacting $\mathrm{NH}_{2}$-DNA $(14.1 \mathrm{nmol})$. Additionally, reverse-phase HPLC checking of post-coupling washings did not allow detection of any unbound $\mathrm{NH}_{2}$-DNA probe (UV-diode array detection, $\lambda_{\max }=260 \mathrm{~nm}$ ). 